\title{
PURIFICATION AND CHARACTERIZATION METHODS FOR LIGNIN BIOMASS AS A POTENTIAL PRECURSOR FOR CARBON MATERIALS
}

\author{
KATIA SANTOS DAMACENA NUNES ${ }^{*}$ and LUIZ CLAUDIO PARDINI ${ }^{* *}$ \\ *Aeronautic Institute of Technology - ITA, Marechal Eduardo Gomes Sq., \\ 50 Vila das Acácias, São José dos Campos, Brasil \\ *Aeronautics and Space Institute - IAE/AMR, Marechal Eduardo Gomes Sq., \\ 50 Vila das Acácias, São José dos Campos, Brasil \\ ๔ Corresponding author: K. Santos Damacena Nunes, katiadamacen@hotmail.com
}

Received June 22, 2018

\begin{abstract}
A purification process has been optimized for eucalyptus and sugarcane lignins in order to meet the specification requirements for obtaining high-quality carbon materials free of contaminants. Fluorescence XR was used to determine the inorganic content, comprising $\mathrm{Ca}, \mathrm{Fe}, \mathrm{Al}, \mathrm{Si}$ and $\mathrm{Na}$. The ash content after the purification process met the minimum requirements for use as a precursor of carbon materials. Elemental analyses were used to determine the contents of C, N, H, S and O. Fourier transform infrared (FTIR) spectroscopy and the second derivative analysis were used to determine the levels of guaiacyl, syringyl and intramolecular hydrogen interactions. FTIR, thermogravimetric analysis (TGA) and differential scanning calorimetry (DSC) showed that sugarcane lignin has higher thermal stability and intermolecular interactions than kraft lignin. Carbon-13 nuclear magnetic resonance $\left({ }^{13} \mathrm{C} \mathrm{NMR}\right)$ spectroscopy was used for the quantitative determination of structural chemical groups and contaminants. The results indicated a large potential for the application of the obtained lignins as precursors for carbon materials.
\end{abstract}

Keywords: kraft lignin, sugarcane lignin, purification, characterization

\section{INTRODUCTION}

Biomass is a key feedstock for the renewable production of fuels, chemicals and energy. ${ }^{1-4}$ Lignin is a renewable resource derived from biomass. It is an aromatic heteropolymer mainly found in the secondary wall of wood cells. It is the most abundant and important polymeric organic substance in the vegetable kingdom, after cellulose $^{5-8}$ Recently, it has been shown that lignin can potentially be a valuable low-cost precursor material for the production of highperformance carbon materials, such as carbon fibers. ${ }^{9,10}$ Lignin can be obtained from various sources. The most abundant source for this material comes from the cellulose kraft process (paper mills). Recently, a new abundant source of lignin, based on the sugarcane bagasse process, has attracted the attention of many researchers. ${ }^{15}$ The focus, in this work, is on kraft and sugarcane lignins to be used in the production of carbon materials.
By definition, lignin is a random, amorphous polyphenolic three-dimensional polymeric network, with a weight-average molecular weight $(\mathrm{Mw})$ of 2400. It is a highly aromatic and highly polymerized substance that does not possess a uniform, homogenous and well-defined structure. $^{9-} 11,26$ However, it consists of wellestablished repeating units of precursors (i.e., coniferyl alcohol, sinapyl alcohol, p-coumaryl alcohol). In Figure 1, the most common phenolic monomers from lignin are presented. Because of such heterogeneity, it is not possible to associate a defined structure to lignin, although some representative models have been proposed. ${ }^{12-14}$

All over the world, a large amount of biomass waste is available, which represents a great potential for lignin production. In the case of wood processing for papermaking, the main byproduct is black liquor. In the case of sugarcane lignin, the by-product is bagasse. In the first case, lignin is obtained by chemical treatments from 
black liquor, usually through a process named LignoBoost. $^{15,16}$ In the second case, the lignin obtained is called grass lignin. ${ }^{15}$ Other pretreatment methods have been developed in the last decades to obtain lighter, higher-quality lignin. However, some of the associated challenges arise from the recalcitrant nature of lignocelluloses, including cellulose and hemicellulose, which are closely linked to lignin, making it difficult to obtain pure lignin. ${ }^{17}$ Processes such as autohydrolysis, soda and organosolv are methods that strongly affect the physicochemical properties of lignin. ${ }^{18}$ Other alternatives would be those based on enzymatic systems, such as cellulolytic enzymatic lignin (CEL) and enzymatic mild acidolyses lignin (EMAL), which have been considered as having higher yield and lower degradation. ${ }^{18}$ A variety of pretreatment methods have been developed, but only a few have reached the marketing stage. The membrane process, mainly ultrafiltration (UF) and nanofiltration (NF), has been used in pulp and paper mills since the late 1960s. Increased demands for environmental protection, energy savings and recovery of valuable products have accentuated the need to obtain a lignin suitable for the different industrial proposals. ${ }^{19}$

The annual world lignin production is over 70 million tons and $95 \%$ is burned for energy generation. The remaining $5 \%$ is used for other commercial applications, including additives, dispersants, binders or surfactants. ${ }^{16}$

There is a growing interest in the development of high performance carbon materials, particularly carbon fibers, produced directly from biomass materials, due to the availability of these materials and their low cost. ${ }^{13,20}$ Nowadays, highperformance carbon fibers are produced from polyacrylonitrile (PAN). ${ }^{9,21}$ However, PAN is too expensive for large-scale use in massive volume markets, such as transportation applications, restricting their usage to the aerospace, wind energy and marine markets. ${ }^{9}$ Currently, PAN is produced from petroleum feedstock. It is well known that petroleum has a volatile market in terms of price stability and availability. Therefore, alternative precursor sources are interesting to investigate for use as raw materials for carbon fibers. ${ }^{9}$
Composites account for only about 1 percent of the total structural materials market by volume. Therefore, there are many opportunities to increase their usage in various other industries by replacing traditional materials, such as steel and aluminum. $^{22}$ For lightweight transportation vehicles, carbon fiber, in the form of composite material, is a logical alternative. ${ }^{23}$

Lignin has been studied since the 1970s as a suitable precursor for carbon fiber. ${ }^{24}$ However, only recently, it has gained substantial attention as a low-cost source for a wide range of carbon materials, especially carbon fibers. ${ }^{10,25}$ Typical specifications of lignin to be used as a precursor for carbon fiber require $1.0 \%$ by weight of ashes at $800{ }^{\circ} \mathrm{C}$, volatile material less than $5 \%$ by weight at $250{ }^{\circ} \mathrm{C}$ and absence of coarse particles with the diameter greater than $1 \mu \mathrm{m} .^{8,27}$ Besides, previous lignin studies reviewed the uses of a variety of lignin types and lignin polymer blends as precursors for carbon fiber. ${ }^{20}$ The matter has been the subject of many works around the world, since the legislation stipulates low fuel consumption in the transportation industry, recyclability and low-cost raw materials as mandatory requirements. ${ }^{9}$

The present work had the objective of studying kraft and sugarcane lignins to be used as precursor raw materials for achieving carbonbased materials. First, a test was performed using kraft lignin, without the use of any purification process, in the preparation of polymeric blends. ${ }^{18,23,34}$ The preliminary results indicated that the lignin would not be suitable for this application because of the large amount of debris, sugar, ashes and inconsistent particle sizes. Different particle sizes in the lignin composition would not provide an adequate material to be used for obtaining polymeric blends. Then, better methods of purification were investigated, in an attempt to find a way to obtain lignins suitable for the intended application. One of the objectives of this study was to investigate methods for lignin purification that would make it possible to have a low-cost precursor material suitable for the production of polymeric blends. Other objectives of this work included the characterization of the kraft and sugarcane lignins as suitable biomass materials that could be used to provide sustainable carbon fiber precursors. 


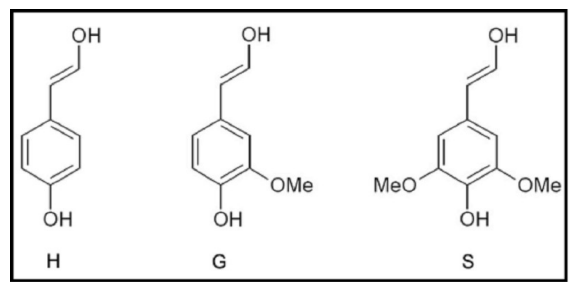

Figure 1: Most common monolignols in lignin (H: p-coumaryl alcohol; G: coniferyl alcohol; S: sinapyl alcohol) ${ }^{9-11}$

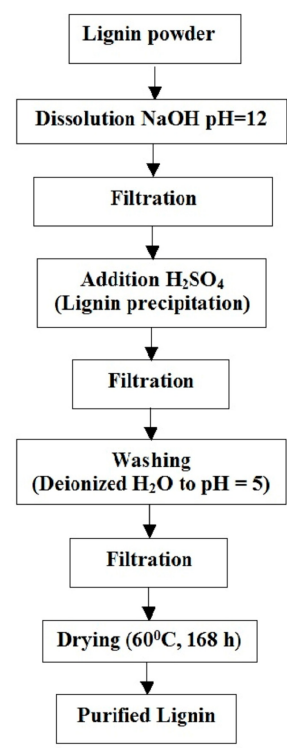

Figure 2: Lignin purification scheme

\section{EXPERIMENTAL}

Materials

Kraft lignin and sugarcane lignin were used in this work. The kraft lignin is a hardwood lignin that was obtained from eucalyptus, by using the LignoBoost process, ${ }^{22}$ and was purchased from Fibria S.A. The sugarcane bagasse lignin (sugarcane lignin) is a grass type lignin that was obtained from alkaline processing, ${ }^{10}$ and provided by CNPEM (Centro Nacional de Pesquisa em Energia e Materiais). Chemicals, such as $\mathrm{NaOH}$ (IMPEX, product number 20105IQBC) and $\mathrm{H}_{2} \mathrm{SO}_{4}$ (ULTRA, product number QX19522), were used in the purification process. The quantification of $\mathrm{C}, \mathrm{N}, \mathrm{H}, \mathrm{S}$ and $\mathrm{O}$ content in the lignin samples was performed using a calibration curve with minimum requirements for the correlation coefficient $\left(\mathrm{r}^{2}\right)$ greater than 0.99 for the reference analytical standard. The analytical standard used for quantification of the contained sulfur was petroleum coke (LECO, USA), with the following contents: sulfur $(\%)$ : $5.67 \pm 0.14$; volatile $(\%)$ : $13.0 \pm 0.70$; ash $(\%): 0.27 \pm 0.06$. The analytical standard used for quantification of the elements was EDTA (LECO, USA), with the following contents: carbon (\%): 41.07 \pm 0.13 ; hydrogen $(\%)$ : $5.5 \pm 0.03$; nitrogen $(\%)$ : $9.56 \pm 0.02$.

\section{Methodology}

Lignin purification

The lignin (kraft and sugarcane) was purified in order to proceed with the characterization steps. The purification follows the scheme shown in Figure 2. Both kraft and sugarcane bagasse lignin started from a brown powder material. In a container of $30 \mathrm{~L}, 500 \mathrm{~g}$ of lignin powder was placed, followed by the addition of $25 \mathrm{~L}$ of distilled $\mathrm{H}_{2} \mathrm{O}$. Under vigorous stirring, $\mathrm{NaOH}$ was added until a $\mathrm{pH}$ of 12 .

After complete dissolution of the lignin, filtration was accomplished for removal of particulates and impurities larger than $1 \mu \mathrm{m}$. Then, under vigorous stirring, $\mathrm{H}_{2} \mathrm{SO}_{4}$ was added to the filtrate until $\mathrm{pH}=2$, in order to precipitate the whole filtered lignin. The precipitated lignin, in the form of a gel, was allowed to stand for $24 \mathrm{~h}$. Afterwards, the precipitated lignin was 
placed on a sturdy filter to be washed until $\mathrm{pH}$ 4.5-5.0 was reached. At $\mathrm{pH}=5$, the washed sugarcane and kraft lignins were placed in an oven at a temperature of $60{ }^{\circ} \mathrm{C}$ for a week. Purified and dried lignin was kept in a suitable container to avoid moisture absorption.

\section{Lignin milling}

The purified lignin underwent a milling process, in a Marconi hammer mill. The purified lignin powder was added to the hammer mill in batches of small amounts. After milling, the powder passed through a sieve of one hundred mesh $(0.15 \mathrm{~mm})$ to separate the powder from larger lignin particles. The larger particles returned to the milling process. After the milling process, all purified lignin passed through a sifting process. Sieves of 200 mesh $(0.074 \mathrm{~mm})$ were used.

\section{$X$-Ray fluorescence}

X-ray fluorescence analysis was used in order to find out the content of contaminant elements in the raw materials. Samples of kraft lignin and sugarcane lignin were analysed after the purification process. The equipment used for the analysis was the PANalyticalAxios, Tube: Rh, power: $2.5 \mathrm{~W}$; software: Super Q manager. Samples were prepared by pressing into tablets.

\section{Determination of ash content in lignin}

Determination of ash in lignin was done using an EDG CON 3P model 3000 oven and the weight was recorded on a Mettler Toledo balance, model AB265$\mathrm{S} /$ Fact. Initially, the porcelain crucible was pyrolysed at $800{ }^{\circ} \mathrm{C}$ for two hours and cooled in a desiccator under vacuum at room temperature. Approximately $2 \mathrm{~g}$ of lignin was weighed in the porcelain crucible. The lignin was initially pyrolysed at $300{ }^{\circ} \mathrm{C}$ for one hour and then the temperature was raised to $800{ }^{\circ} \mathrm{C}$ and maintained at this level for two more hours. After the calcination was completed, the porcelain crucible containing the ash was cooled in a desiccator under vacuum at room temperature and the sample was weighed.

\section{Elemental analyses}

Elemental analyses were conducted on a CHN 628 (LECO) for Module S and 628S (LECO) for module CHN. The detection mode for $\mathrm{N}$ was thermal conductivity and for $\mathrm{S}, \mathrm{C}$ and $\mathrm{H}$ the detection mode was IR. Oxygen gas was used to burn all the raw materials and helium was used for gas drag. The elemental analysis of $\mathrm{C}, \mathrm{N}$ and $\mathrm{H}$ was done by weighing $0.100 \mathrm{~g}$ of raw materials and completely incinerating them at $1050{ }^{\circ} \mathrm{C}$. The oxygen content was obtained by difference according to the guidelines of Bech et $a l .{ }^{29}$ and Protásio et $a l^{30}$ The elemental analysis for sulfur was done by weighing $\pm 0.1000 \mathrm{~g}$ of the sample in a porcelain crucible and by complete incineration of the sample at $1450{ }^{\circ} \mathrm{C}$. Detection was accomplished in the IR mode.

\section{Fourier transform infrared spectroscopy}

Fourier transform infrared spectroscopy was used for the characterization of the purified kraft lignin and sugarcane lignin used in this work. In the case of lignins, Fourier transform infrared spectroscopy (FTIR) can characterize the functional groups, allowing to determine different amounts of guaiacyl (G) and syringyl (S) groups. Infrared spectra of the purified kraft and sugarcane lignins were taken using the Fourier transform infrared/universal attenuated total reflectance (FTIR/UATR) technique, with $120 \mathrm{~N}$ and 20 scans at room temperature. Measurements were recorded on a Perkin Elmer 20 PG. The second derivative spectra from FTIR were used to determine different types of noncovalent interactions of lignins, and were also useful for the determination of the number of hidden peaks. All the data were analyzed and compared on the basis of the peak areas performed by maximum likelihood peak fitting. Deconvolution was performed using the Gaussian shape and a full width at half maximum (fwhm) of $20-40 \mathrm{~cm}^{-1}$ was taken to ensure the resolution of the peaks without overfitting and a good selection of the peaks as a measure of spectral intensity. The noncovalent interactions explain the differences in thermal and mechanical properties between hardwood lignin and sugarcane bagasse lignin. ${ }^{6,27,28,38,39}$ FTIR analysis was done in the transmittance mode. Values for absorbance (A) can be obtained from the percent transmittance by: $\mathrm{A}=2-\log _{10}(\% \mathrm{~T})$.

\section{Thermal analysis by DSC and TGA}

Thermogravimetric analysis (TGA) has been widely used to evaluate the thermal decomposition process of solid-state materials. ${ }^{41}$ In this work, the thermal properties of lignins were investigated by using thermogravimetric analysis (TGA) and differential scanning calorimetry (DSC). The thermal stability and the carbon yield of the lignin samples were determined on a TGA from TA Instruments. TGA results were obtained under nitrogen atmosphere in a temperature range from room temperature (RT) to $1000{ }^{\circ} \mathrm{C}$, at a heating rate of $20{ }^{\circ} \mathrm{C} / \mathrm{min}$. DSC scans were obtained on a Perkin Elmer apparatus, Pyris Instruments, run from room temperature to $250{ }^{\circ} \mathrm{C}$, at a heating rate of $20{ }^{\circ} \mathrm{C} \mathrm{min}{ }^{-1}$ under nitrogen atmosphere. The samples were hermetically sealed in aluminum pans. ${ }^{28}$ These experiments were carried out on $\sim 6-8 \mathrm{mg}$ samples heated in an inert environment, so as to inhibit any secondary reactions due to fragments, such as $\mathrm{HCN}, \mathrm{CO}, \mathrm{NH}_{3}$ released in the combustion process. ${ }^{28}$ The glass transition temperature $\left(\mathrm{T}_{\mathrm{g}}\right)$ was recorded as the midpoint temperature of the heat capacity transition on the first heating run. 


\section{$1 D^{13}$ C NMR}

Nuclear magnetic resonance spectroscopy $\left({ }^{13} \mathrm{C}\right.$ NMR) is useful to identify the interaction of molecules, providing a detailed quantitative determination of the amounts of the different structural units in lignin. ${ }^{29,30}$ For recording NMR spectra, the samples were prepared by accurately weighing predried lignin and dissolving it in deuterated dimethylsulfoxide-d6 (DMSO-d6). Typical sample concentrations were of the magnitude of $\sim 200 \mathrm{mg} \mathrm{cm}^{-3}$ for the lignin samples. The ${ }^{13} \mathrm{C} \mathrm{RMN}$ analysis was carried out in Bruker 400 Top Spin equipment, version 2.1 (Bruker BioSpin GmbH). The module of "SolventDetect" was used within a "Top Spin" designed to allow the spectrometer to detect and subsequently lock on the solvent. ${ }^{29}$

\section{RESULTS AND DISCUSSION \\ $\mathrm{X}$-ray fluorescence}

$\mathrm{X}$-ray fluorescence results are shown in Table 1 for kraft lignin and in Table 2 for sugarcane lignin. Metal contaminants in the lignins were recorded and the results are shown in relation to ash content by weight. The type and quantity of contaminants give an idea about the history of salts and minerals that were absorbed by the plant during the period of growth. X-ray fluorescence results revealed the following inorganic contaminants in kraft lignin: $\mathrm{Ca}, \mathrm{Fe}, \mathrm{Na}, \mathrm{Al}$ and $\mathrm{Si}$, while in sugarcane lignin the contaminants were: $\mathrm{Ca}, \mathrm{Si}, \mathrm{Fe}, \mathrm{Mo}, \mathrm{Ti}, \mathrm{Al}, \mathrm{Na}, \mathrm{Cl}, \mathrm{Cu}, \mathrm{Cr}, \mathrm{Zr}$ and $\mathrm{P}$. The content of contaminant elements in sugarcane lignin is much higher than that in kraft lignin. Therefore, a lower amount of contaminants, as shown by kraft lignin, is more favorable for the use of the material as precursor for obtaining carbon materials. ${ }^{15,33}$

\section{Ash content of lignins}

Before purification, the ash percentage at 800 ${ }^{\circ} \mathrm{C}$ for the kraft lignin was $1.07 \mathrm{wt} \%$ and for the sugarcane lignin it was $1.72 \mathrm{wt} \%$. In addition, both lignin types showed high content of coarse particles with the diameter above $1 \mu \mathrm{m}$. After the purification process, the ash analysis at $800{ }^{\circ} \mathrm{C}$ indicated $0.06 \mathrm{wt} \%$ for the kraft lignin and 0.09 $\mathrm{wt} \%$ for the sugarcane lignin. The specifications for lignin proposed as precursor for carbon materials require an ash content below $1.0 \mathrm{wt} \%$ at $800{ }^{\circ} \mathrm{C} .{ }^{8,27}$ Both lignin types have ash contents lower than $1.0 \%$ at $800{ }^{\circ} \mathrm{C}$, volatile material lower than $5 \%$ at $250{ }^{\circ} \mathrm{C}$ and no content of dross particles with the diameter above $1 \mu \mathrm{m}$. The ash content analysis showed that the lignin contaminant content, after the purification process, is lower than $0.1 \mathrm{wt} \%$. Therefore, the kraft and sugarcane lignins correspond to the specifications with regard to ash content for use as precursors for carbon materials, including carbon fibers.

Table 1

Content of inorganic elements in kraft lignin

\begin{tabular}{cc}
\hline Compound & Concentration $(\%)$ \\
\hline $\mathrm{Ca}$ & 0.02 \\
$\mathrm{Fe}$ & 0.01 \\
$\mathrm{Na}$ & 0.01 \\
$\mathrm{Al}$ & 0.01 \\
$\mathrm{Si}$ & 0.01 \\
\hline
\end{tabular}

Table 2

Content of inorganic elements in sugarcane lignin

\begin{tabular}{cccc}
\hline Compound & Concentration $\left(\times 10_{\%}^{-2}\right)$ & Compound & Concentration $\left(\times 10_{\%}^{-2}\right)$ \\
\hline $\mathrm{Si}$ & 2.7 & $\mathrm{Mo}$ & 0.25 \\
$\mathrm{Fe}$ & 2.5 & $\mathrm{Na}$ & 0.12 \\
$\mathrm{Ti}$ & 1.2 & $\mathrm{Cr}$ & 0.12 \\
$\mathrm{Al}$ & 1.2 & $\mathrm{Ca}$ & 0.06 \\
$\mathrm{Cl}$ & 0.38 & $\mathrm{Zr}$ & 0.06 \\
$\mathrm{Cu}$ & 0.25 & $\mathrm{P}$ & 0.06 \\
\hline
\end{tabular}


KATIA SANTOS DAMACENA NUNES and LUIZ CLAUDIO PARDINI

Table 3

Elemental analysis of kraft lignin (ash content: $0.06 \%$ at $800{ }^{\circ} \mathrm{C}$ )

\begin{tabular}{lccccc}
\hline Sample & N (\%) & C (\%) & H (\%) & O (\%) & S (\%) \\
\hline Sample 1 & 0.15 & 62.74 & 5.86 & 26.90 & 2.19 \\
Sample 2 & 0.12 & 62.24 & 5.88 & 27.36 & 2.24 \\
Sample 3 & 0.12 & 62.10 & 5.87 & 27.54 & 2.22 \\
Average & 0.13 & 62.36 & 5.87 & 27.27 & 2.21 \\
\hline
\end{tabular}

Table 4

Elemental analysis of sugarcane lignin (ash content: $0.09 \%$ at $800{ }^{\circ} \mathrm{C}$ )

\begin{tabular}{lccccc}
\hline Sample & $\mathrm{N}(\%)$ & $\mathrm{C}(\%)$ & $\mathrm{H}(\%)$ & $\mathrm{O}(\%)$ & $\mathrm{S}(\%)$ \\
\hline Sample 1 & 0.58 & 58.42 & 6.11 & 31.40 & 0.13 \\
Sample 2 & 0.58 & 58.25 & 6.15 & 31.54 & 0.13 \\
Sample 3 & 0.56 & 58.04 & 6.18 & 31.74 & 0.13 \\
Average & 0.57 & 58.20 & 6.15 & 31.56 & 0.13 \\
\hline
\end{tabular}

\section{Elemental analysis}

The lignin structure is dependent on wood species and processing conditions. Commercially, lignin is obtained as a by-product of "wood free" papermaking. ${ }^{40}$ Elemental analysis is used to study the structure of lignin and to determine the content of $\mathrm{C}, \mathrm{H}, \mathrm{N}, \mathrm{S}$ and $\mathrm{O} .{ }^{15}$ In Tables 3 and 4, the results of the elemental analysis are shown. According to Bech et al. ${ }^{29}$ and Protásio et al. ${ }^{30}$ the oxygen concentration in a raw material can be found after the determination of the concentration for all other element contents $(\mathrm{C}, \mathrm{H}, \mathrm{N}, \mathrm{S}$ and ashes).

Table 3 shows that the kraft lignin used in this work has around $62 \%$ carbon in its molecule, followed by about $27 \%$ oxygen. The carbon content has great importance, since it substantially affects the efficiency of carbon production after the heat treatment process. On the other hand, sugarcane lignin has around 58\% carbon in its molecule, followed by $31.5 \%$ oxygen. These values are similar to those found for the kraft lignin, despite the different origins of the materials. Comparing the results obtained for the kraft and sugarcane lignins with the ones reported in the work of Marin ${ }^{15}$ it is possible to conclude that the results are quite similar.

The analyzed samples of kraft and sugarcane lignins also showed the following characteristics: nitrogen amount less than $0.6 \%$ by weight; carbon amount less than $63 \%$ by weight, hydrogen amount around $6 \%$ by weight and oxygen amount nearly $30 \%$ by weight (with a slightly lower level for kraft lignin when compared with that for sugarcane lignin). The percentage amounts found for kraft lignin were the following: $\mathrm{C}=62.36 \%$, $\mathrm{H}=5.87 \%, \mathrm{~N}=0.13 \%, \mathrm{~S}=2.21 \%$ and $\mathrm{O}=$
27.27\%, while for sugarcane lignin they were: $\mathrm{C}$ $=58.20 \%, \mathrm{H}=6.15 \%, \mathrm{~N}=0.57 \%, \mathrm{~S}=0.13 \%$ and $\mathrm{O}=31.56 \%$. Oak Ridge National Laboratory has published the necessary requirements for suitable raw materials to obtain lignin for use as precursor for carbon materials. One requirement is that the minimum carbon content must be above $40 \%{ }^{23}$ Therefore, both lignin types showed satisfactory carbon contents. According to the obtained results, the kraft lignin contains $62.5 \%$ carbon and sugarcane lignin contains $58.2 \%$. Comparing both lignins, the higher the carbon content, the more appropriate is the lignin to be used as carbon material precursor. Therefore, kraft lignin has higher potential to be employed for this application.

\section{Characterization by FTIR/UATR-120N}

FTIR/UATR analysis is a universal sampling method for simple IR spectroscopic analysis. It has a great advantage over other probe analyses because the sample preparation is much easier, since it requires only a good contact between the sample and the top plate crystal. Besides, this technique allows reading a large number of samples in a short time. For lignin samples, the FTIR/UATR technique is more advantageous because the samples are analyzed without interference from previous preparation. Lignin samples are analyzed as dried powder. The infrared spectra obtained for the kraft and sugarcane lignins are presented in Figure 3. The peak positions of the bands in the FTIR spectra are summarized in Table 5 for the lignin samples, based on literature data. ${ }^{6,27}$

As sugarcane lignin is a grass type lignin, its FTIR spectra show typical softwood lignin 
assignments: a band at $1270 \mathrm{~cm}^{-1}$ and $1219 \mathrm{~cm}^{-1}$ assigned to $\mathrm{C}-\mathrm{O}$ of guaiacyl ring, a band at 1120 $\mathrm{cm}^{-1}$ related to aromatic C-H in-plane deformation in the guaiacyl ring, a band at $1030 \mathrm{~cm}^{-1}$ assigned to $\mathrm{C}-\mathrm{O}$ deformations of secondary alcohols and aliphatic ethers and a band at $915 \mathrm{~cm}^{-1}$ assigned to $\mathrm{C}-\mathrm{H}$ out-of-plane in positions 2,5 and 6 (G units). Softwood lignin, often referred to as guaiacyl lignin, is mainly composed of coniferyl alcohol units (p-coumaryl), which make up more than $95 \%$ of the structural units in this lignin. On the other hand, for hardwood lignins, there is an assignment at $1323 \mathrm{~cm}^{-1}$ related to $\mathrm{C}-\mathrm{O}$ of the syringyl ring and a band at $1111 \mathrm{~cm}^{-1}$ assigned to aromatic $\mathrm{C}-\mathrm{H}$ deformation in the syringyl ring. Hardwood lignin is composed of coniferyl alcohol and sinapyl alcohol derived units in varying proportions, and is commonly referred to as guaiacyl-syringyl lignin. ${ }^{39}$

The composition of arboreal wood depends mainly on the tree taxonomy and the environmental factors of the tree growing region. The lignin of softwood trees is composed of guaiacyl units, whereas that of hardwood contains both guaiacyl and syringyl moieties. ${ }^{43}$

Based on the FTIR spectra of the sugarcane and kraft lignins, both of them showed typical bands. Both lignin samples presented a broad band attributed to $\mathrm{OH}$ stretching $(v \sim 3412-3460$ $\mathrm{cm}^{-1}$ ), and peaks corresponding to C-H stretching of the methyl and methylene group $(v \sim 2842$ $\left.3000 \mathrm{~cm}^{-1}\right)$ and the methyl group of methoxyl $(v \sim$ 2689-2880 $\mathrm{cm}^{-1}$ ). The most characteristic vibrations of lignins correspond to those of aromatic rings at approximately $1600 \mathrm{~cm}^{-1}, 1513$ $\mathrm{cm}^{-1}$ and $1420 \mathrm{~cm}^{-1}$. 6,27

The lignin composition could be studied by the ratio between syringyl and guaiacyl products $(\mathrm{S} / \mathrm{G})$. This parameter is used to differentiate between softwood lignin composed of the guaiacyl unit and hardwood lignin composed of guaiacyl and syringyl units. ${ }^{43}$ The ratio between the band intensities at 2919, 1270 and $915 \mathrm{~cm}^{-1}$ for sugarcane lignin and between the band intensities at 2937, 1323 and $912 \mathrm{~cm}^{-1}$ for kraft lignin was used for determining the differences in the guaiacyl (G) and syringyl (S) groups. The results are presented in Table 6 and show the differences in the quantities of $S$ and $G$ groups that were determined for both lignins. ${ }^{38}$ The results shown in Table 6 for sugarcane lignin reveal a composition made only of $G$ units. On the other hand, kraft lignin is composed of a mixture of $\mathrm{S}$ and $\mathrm{G}$ units, where $\mathrm{S}$ units predominate. For sugarcane lignin, the results show similarity with softwood lignin as it consists only of guaiacyl propane (G units). ${ }^{39}$

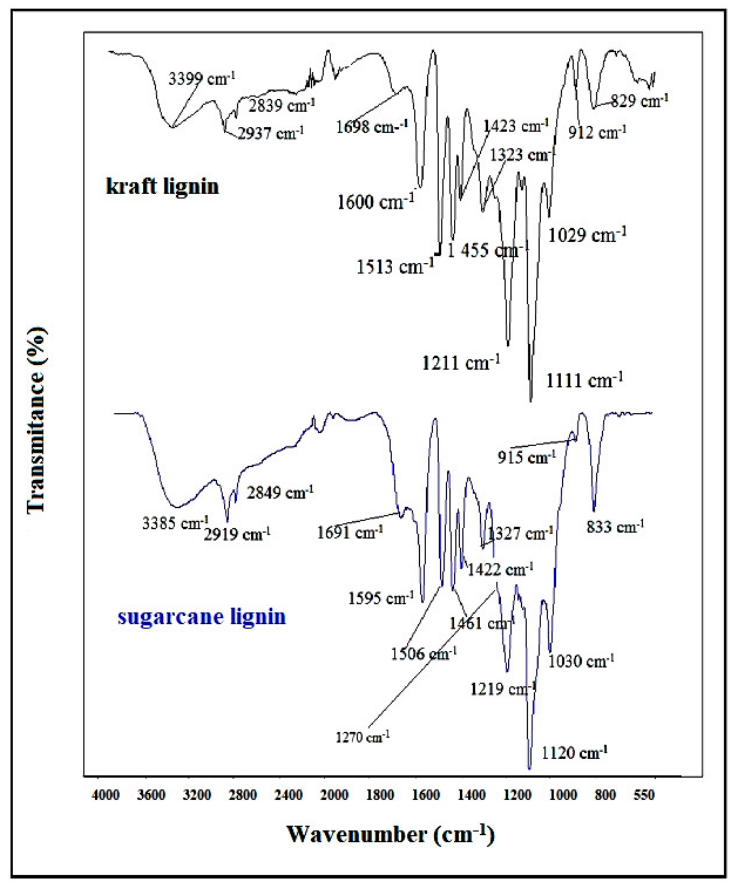

Figure 3: FTIR spectra obtained for kraft lignin (top) and sugarcane lignin (bottom) 
KATIA SANTOS DAMACENA NUNES and LUIZ CLAUDIO PARDINI

Table 5

IR vibrational band assignments for kraft lignin and sugarcane lignin

\begin{tabular}{|c|c|c|c|}
\hline \multicolumn{2}{|c|}{ Kraft lignin (hardwood) } & \multicolumn{2}{|c|}{ Sugarcane lignin (grass) } \\
\hline Wavenumber $\left(\mathrm{cm}^{-1}\right)$ & Assignment & Wavenumber $\left(\mathrm{cm}^{-1}\right)$ & Assignment \\
\hline 829 & $v(-\mathrm{CH})$ guaiacyl & 833 & $v(-\mathrm{CH})$ guaiacyl \\
\hline 912 & $\begin{array}{c}\delta, v(\mathrm{CH}) \text { out-of-plane in } \\
\text { positions } 2,5 \text { and } 6 \text { (G units) }\end{array}$ & 915 & $\begin{array}{c}\delta, v(\mathrm{CH}) \text { out-of-plane in } \\
\text { positions } 2,5 \text { and } 6 \text { ( } \mathrm{G} \text { units) }\end{array}$ \\
\hline 1029 & $\begin{array}{c}v(\mathrm{C}-\mathrm{O}) \text { ester } \\
v(\mathrm{C}-\mathrm{C}) \text { aromatic }\end{array}$ & 1030 & $\begin{array}{c}\delta(\mathrm{CH}) \text { aromatic ring in } \\
\text { methoxy groups }\end{array}$ \\
\hline 1111 & $v(\mathrm{C}-\mathrm{O})$ & 1120 & $\delta(\mathrm{CH})$ in guaiacyl units \\
\hline 1211 & $\begin{array}{c}v(\mathrm{C}-\mathrm{C} ; \mathrm{C}-\mathrm{O} ; \mathrm{C}=\mathrm{O}) \text { phenolic } \\
\text { groups }\end{array}$ & 1219 & $\begin{array}{c}v(\mathrm{C}-\mathrm{C} ; \mathrm{C}-\mathrm{O} ; \mathrm{C}=\mathrm{O}) \text { phenolic } \\
\text { groups }\end{array}$ \\
\hline - & - & 1270 & C-O guaiacyl ring \\
\hline 1323 & $\mathrm{C}-\mathrm{O}$ of the syringyl ring & 1327 & $\begin{array}{l}\text { Vibration S ring and } \mathrm{G} \\
\text { condensed }\end{array}$ \\
\hline 1423 & Vibration aromatic ring; $\delta(\mathrm{CH})$ & 1422 & $\begin{array}{l}\text { Vibration aromatic ring; } \delta \\
(\mathrm{CH})\end{array}$ \\
\hline 1455 & $\delta\left(\mathrm{C}-\mathrm{H} ; \mathrm{CH}_{3} ; \mathrm{CH}_{2}\right)$ & 1461 & $\delta\left(\mathrm{C}-\mathrm{H} ; \mathrm{CH}_{3} ; \mathrm{CH}_{2}\right)$ \\
\hline 1513 & Vibration aromatic ring & 1506 & Vibration aromatic ring \\
\hline 1600 & $v(\mathrm{C}-\mathrm{C} ; \mathrm{C}=\mathrm{O})$ aromatic & 1595 & $v(\mathrm{C}-\mathrm{C} ; \mathrm{C}=\mathrm{O})$ aromatic \\
\hline 1698 & $v(\mathrm{C}=\mathrm{O})$ carbonyl & 1691 & $v(\mathrm{C}=\mathrm{O})$ carbonyl \\
\hline 2839 & $\begin{array}{c}\delta(\mathrm{CH}) \text { in methyl and } \\
\text { methylene units }\end{array}$ & 2849 & $\begin{array}{c}\delta(\mathrm{CH}) \text { in methyl and } \\
\text { methylene units }\end{array}$ \\
\hline 2937 & $\begin{array}{l}v(\mathrm{C}-\mathrm{H}) \text { methyl and methylene } \\
\text { groups }\end{array}$ & 2919 & $\begin{array}{l}v(\mathrm{C}-\mathrm{H}) \text { methyl and methylene } \\
\text { groups }\end{array}$ \\
\hline 3399 & $v(\mathrm{OH})$ alcoholic and phenolic & 3385 & $v(\mathrm{OH})$ alcoholic and phenolic \\
\hline
\end{tabular}

Table 6

Ratio of intensities from absorbance level showing differences in the amount of guaiacyl and syringyl groups present in sugarcane and kraft lignins

\begin{tabular}{cccc}
\hline \multicolumn{2}{c}{ Sugarcane lignin } & \multicolumn{2}{c}{ Kraft lignin } \\
\hline (A) $1270 / 2919$ & (A) $915 / 2919$ & (A) $1323 / 2937$ & (A) $912 / 2937$ \\
\hline $1.44 \pm 0.06$ & $0.52 \pm 0.06$ & $1.80 \pm 0.04$ & $0.59 \pm 0.03$ \\
G units & G units & S units & G units \\
\hline
\end{tabular}

Hydrogen bonding, which is a noncovalent interaction, plays an important role in the thermal and mechanical properties of biopolymers such as lignins. Complex hydrogen-bonding systems present in lignin, grass and hardwood have strong interactions. This reduces the thermal molecular motion of the lignin molecules and could explain the differences in glass transition temperatures. ${ }^{38}$ According to Kubo and Kadla, ${ }^{38}$ the hydroxyl groups in alcoholic and phenolic compounds form several intermolecular and intramolecular hydrogen bonds. The response bands of lignins can be better identified by the second derivative spectra of the FTIR. Figures 4 and 5 show the bands assigned to intermolecular and intramolecular hydrogen bonds that could explain the little differences between kraft and sugarcane lignins as regards thermal and mechanical properties. The assignments for free hydroxyls in alcoholic groups are in the spectrum range of 3640-3616 $\mathrm{cm}^{-1}$. Other bands related to intramolecular hydrogen bonds in phenolic groups occur between $3560-3550 \mathrm{~cm}^{-1}$. Intermolecular hydrogen bonds to phenolic groups and their combinations with alcoholic groups occur between $3520-3480 \mathrm{~cm}^{-1}$. Multiple formations of intermolecular hydrogen bond to phenolic groups and their combinations with alcoholic groups are in the range of $3416-3390 \mathrm{~cm}^{-1}$. Intermolecular hydrogen bonds between biphenols and their combinations with alcoholic groups occur between 3242-3238 $\mathrm{cm}^{-1}$. Multiple formation of an intermolecular bond in biphenols is found in $3219 \mathrm{~cm}^{-1}$. In the range of $3191-3165 \mathrm{~cm}^{-1}$, multiple formation of an intermolecular hydrogen bond between biphenol and other phenolic groups 
is observed. The results of the analysis of the second derivative curves indicate that sugarcane lignin has higher complexity and band intensity than kraft lignin. The band intensity value for hardwood lignin is nearly half of the value for sugarcane lignin and the spectrum exhibits lower complexity. Therefore, FTIR analysis of grass and hardwood lignin revealed differences in the intensity of inter hydrogen bond formation. Aliphatic hydroxyl groups form stronger hydrogen bonds than phenolic hydroxyl groups. In softwood lignins, the linkage between guaiacyl-propane units predominates and there are several types of $\mathrm{C}-\mathrm{C}$ bonds, which likely behave as cross-links between the relatively short, linear chains of phenyl-propane units. These linkages will affect the degree of condensation because they allow a more complex macromolecular network structure. Hardwood lignins possess guaiacyl and syringyl propane in their structures, exhibiting a less complex hydrogen-bonding system than softwood. ${ }^{38,39}$ These characteristics could explain the reason why sugarcane lignin is a little more stable and has a higher $\mathrm{T}_{\mathrm{g}}$ value than kraft lignin.

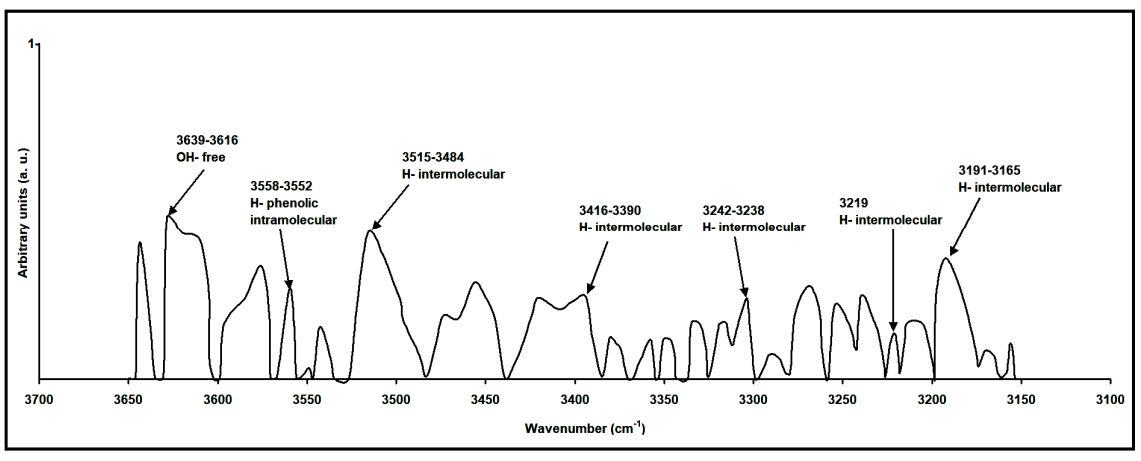

Figure 4: Second derivative FTIR spectra in the $4000-3000 \mathrm{~cm}^{-1}$ range for kraft lignin (syringyl + guaiacyl)

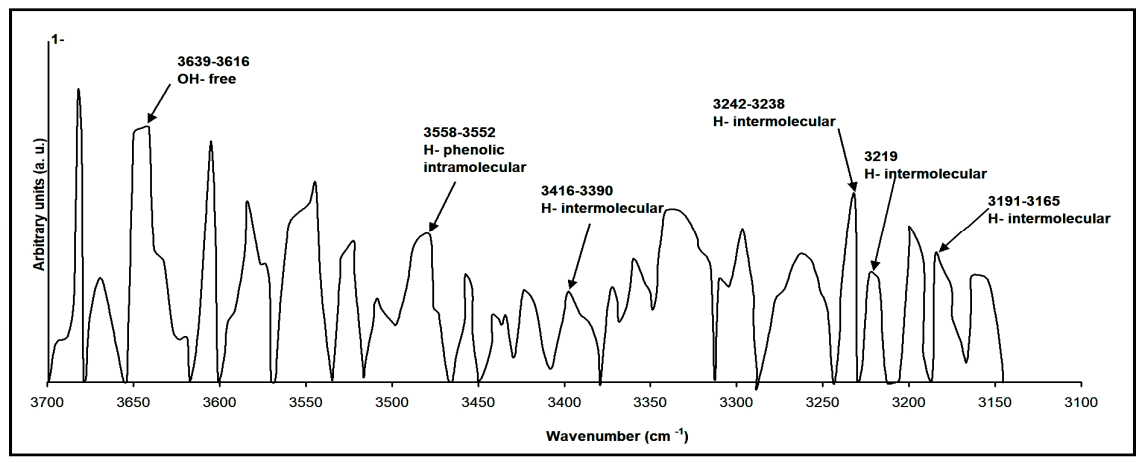

Figure 5: Second derivative FTIR spectra in the $4000-3000 \mathrm{~cm}^{-1}$ range for sugarcane lignin (guaiacyl)

Table 7

Band positions and wavenumber shifts $\left(\Delta v_{\mathrm{O}-\mathrm{H}}\right)$ for the lignin bands obtained from second derivative FTIR spectra

\begin{tabular}{cccc}
\hline \multicolumn{2}{c}{ Band position $\left(\mathrm{cm}^{-1}\right)$} & \multicolumn{2}{c}{$\Delta v_{\mathrm{O}-\mathrm{H}}\left(\mathrm{cm}^{-1}\right)$} \\
\hline Sugarcane & Kraft & Sugarcane & Kraft \\
\hline 3650 & 3640 & 265 & 241 \\
3620 & 3610 & 235 & 211 \\
3560 & 3550 & 175 & 151 \\
3550 & 3540 & 165 & 141 \\
3480 & 3475 & 95 & 76 \\
\hline
\end{tabular}

The average strength of the intermolecular interactions could be estimated by the wavenumber shift $\left(\Delta v_{\mathrm{O}-\mathrm{H}}\right)$ between the free hydroxyl-stretching vibration and that of 
hydrogen-bonded species, related to the center of the hydroxyl band. The wavenumber shift $\left(\Delta v_{\mathrm{O}-\mathrm{H}}\right)$ can be calculated for kraft lignin as $\Delta v_{\mathrm{O}-\mathrm{H}}=13399$ $-v_{\mathrm{O}-\mathrm{H}} \mathrm{l}$, and for sugarcane lignin as $\Delta v_{\mathrm{O}-\mathrm{H}}=13385-$ $v_{\mathrm{O}-\mathrm{H}} \mathrm{l}$, as shown in Table $7 .^{39}$ The interactions between hydroxyl groups in sugarcane lignin are stronger than in kraft lignin. This can be associated with the higher thermal stability and higher energy activation $\left(\mathrm{E}_{\mathrm{a}}\right)$ observed for sugarcane lignin by thermogravimetric analysis. Therefore, a higher amount of energy is necessary to break the hydrogen bonds inter sugarcane lignin groups and this shows that this type of lignin is more stable.

The $\Delta v_{\mathrm{O}-\mathrm{H}}$ values could be obtained from the bands assigned to phenol groups by a linear relationship between the enthalpy of hydrogen bond formation and the $\mathrm{OH}$ wavenumber shift, according to the relation:

$-\Delta \mathrm{H}(\mathrm{kcal} / \mathrm{mol})=0.016 \Delta v_{\mathrm{O}-\mathrm{H}}+0.63$

The $\Delta v_{\mathrm{O}-\mathrm{H}}$ values obtained from the bands assigned to phenolic groups in lignin at $3560 \mathrm{~cm}^{-1}$ and $3550 \mathrm{~cm}^{-1}$ were used to determine the enthalpy of bound hydrogen. The hydrogen bond distances $(\mathrm{R})$ for the two bands described before were obtained according to an equation proposed by Pimentel and Sederholm: ${ }^{39}$

$\mathrm{R}=2.84-\Delta v_{\mathrm{O}-\mathrm{H}} / 4430$

The enthalpy of hydrogen bond formation between phenolic groups is higher in the sugarcane lignin than in the kraft lignin, as shown in Table 8. The distances of hydrogen bonds in sugarcane lignin are lower than those in kraft lignin. Thus, the donor and acceptor atoms in the $\mathrm{O}-\mathrm{H} \bullet \bullet \mathrm{O}$ hydrogen bond in sugarcane lignin are closer than in kraft lignin. Therefore, the interactions between both atoms are more intense in the sugarcane lignin, which results in stronger intermolecular interactions, higher wavenumber shift and higher enthalpy with respect to the $-\mathrm{OH}$ groups. These results reveal an important aspect of sugarcane lignin thermal stability. ${ }^{38,39}$ The enthalpy of $-\mathrm{OH}$ groups and the hydrogen bond distance values for the lignins were determined, and sugarcane lignin showed values slightly greater than those of kraft lignin.

\section{Thermal characterization of kraft and sugarcane lignins by TGA and DSC Thermal characterization by TGA}

The thermal behavior was characterized by thermogravimetric analysis. The weight losses of lignins were described by the recorded TG/DTG (differential thermogravimetric) curves. Figures 6 and 7 show the TG and DTG curves for hardwood kraft lignin and sugarcane lignin. When lignin is exposed to elevated temperatures, significant physical and chemical changes related to variations in weight, dehydration and oxidation of specimens as a function of temperature and time occur. $^{5}$ The thermal degradation of hardwood kraft lignin and sugarcane lignin is shown in Figures 6 and 7. The analysis indicates that the thermal degradation and the maximum rate of weight loss are observed at $334{ }^{\circ} \mathrm{C}$ for kraft lignin and at $342{ }^{\circ} \mathrm{C}$ for sugarcane lignin. The weight loss is observed in the range between $150{ }^{\circ} \mathrm{C}$ and $1,000{ }^{\circ} \mathrm{C}$. A weight loss of nearly $40 \%$ was found for both lignins up to $1,000{ }^{\circ} \mathrm{C}$. These results are very close to those reported by Poletto, for kraft lignin and softwood lignin. ${ }^{39}$

Both thermogravimetric analyses show a wide temperature range for thermal degradation, observed from $100{ }^{\circ} \mathrm{C}$ to $1,000{ }^{\circ} \mathrm{C}$. The thermal stability of the lignins can be explained by the amount of aromatic rings, different functional groups and chemical bonds. Syringyl and guaiacyl units compose the lignin macromolecules. Ether bonds build these units, and the bonds between syringyl units are easier to split than those between guaiacyl units. This may contribute to higher thermal stability and higher activation energy for the grass lignin, which consists only of guaiacyl propane $\mathrm{G}$ units, compared to hardwood lignin, which is basically composed of syringylpropane units (S units). ${ }^{39}$

Table 8

Enthalpy (-OH) wavenumber shift and hydrogen bond distance values for the lignins studied

\begin{tabular}{lcccc}
\hline \multirow{2}{*}{ Lignin samples } & \multicolumn{2}{c}{$-\Delta \mathrm{H}(\mathrm{kJ} / \mathrm{mol})$} & \multicolumn{2}{c}{$\mathrm{R}(\mathrm{nm})$} \\
\cline { 2 - 5 } & $3560 \mathrm{~cm}^{-1}$ & $3550 \mathrm{~cm}^{-1}$ & $3560 \mathrm{~cm}^{-1}$ & $3550 \mathrm{~cm}^{-1}$ \\
\hline Sugarcane & 14.36 & 13.69 & 2.80 & 2.80 \\
Kraft & 12.77 & 12.14 & 2.81 & 2.81 \\
\hline
\end{tabular}




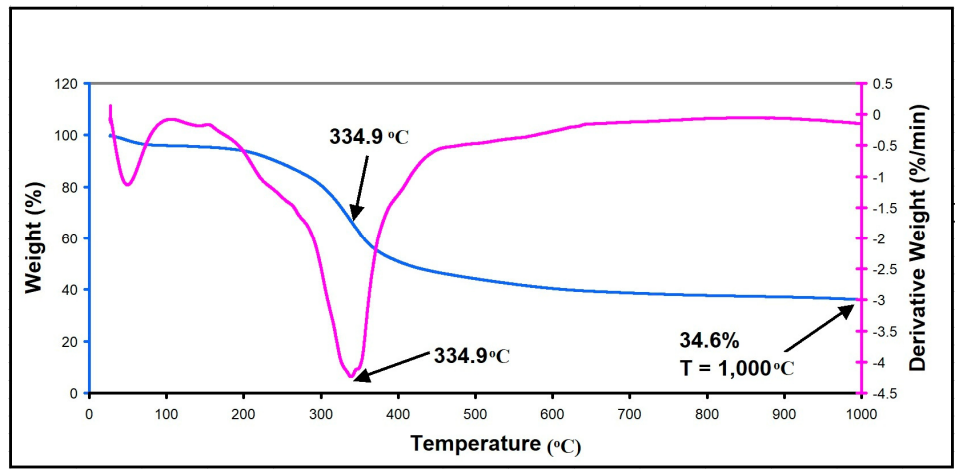

Figure 6: TGA and DTG curves of kraft lignin in the temperature range of $25-1,000{ }^{\circ} \mathrm{C}$ and heat rate of $20^{\circ} \mathrm{C} / \mathrm{min}$

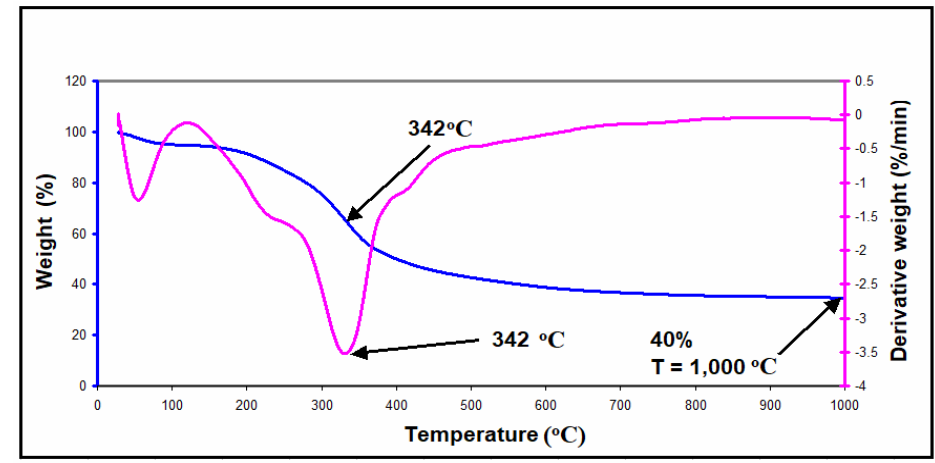

Figure 7: TGA and DTG curves of sugarcane lignin in the temperature range of $25-1,000{ }^{\circ} \mathrm{C}$ and heat rate of $20^{\circ} \mathrm{C} / \mathrm{min}$

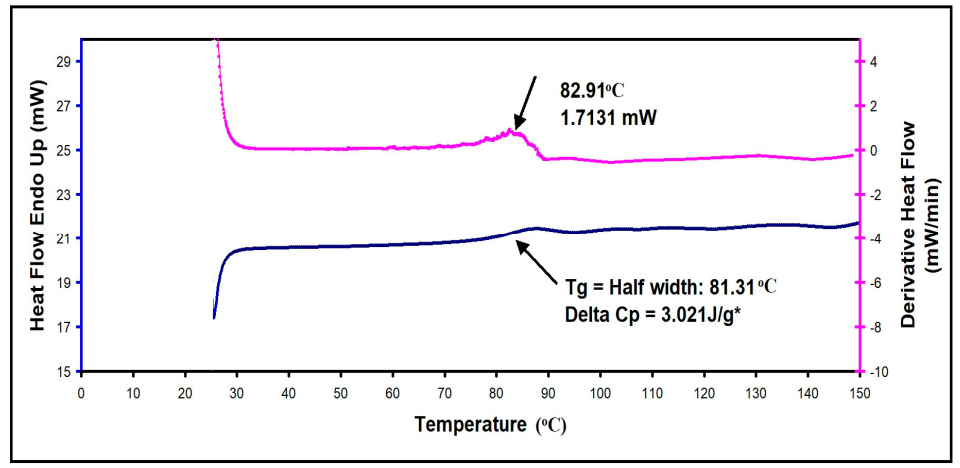

Figure 8: DSC curves of kraft lignin (weight $=5.7 \mathrm{mg}$; temperature rate of $20^{\circ} \mathrm{C} / \mathrm{min} ; \mathrm{N}_{2}$ atmosphere)

It can be seen from the TG/DTG curves that the degradation process for these materials has three stages. In the first stage, which occurs at temperatures lower than $300{ }^{\circ} \mathrm{C}$, a relatively low percentage of weight loss, mainly due to the release of absorbed water and aldehydes, is observed. ${ }^{24}$ The second stage occurs within the range of $300-650{ }^{\circ} \mathrm{C}$, which is the result of the formation of products such as $\mathrm{CO}, \mathrm{CO}_{2}$, benzaldehyde and phenol. In the third stage, when the temperatures are above $650{ }^{\circ} \mathrm{C}$, strong dehydration occurs, and the carbon-link structure is thus gradually formed, generating $\mathrm{CO}$ as a byproduct. $^{24}$ 


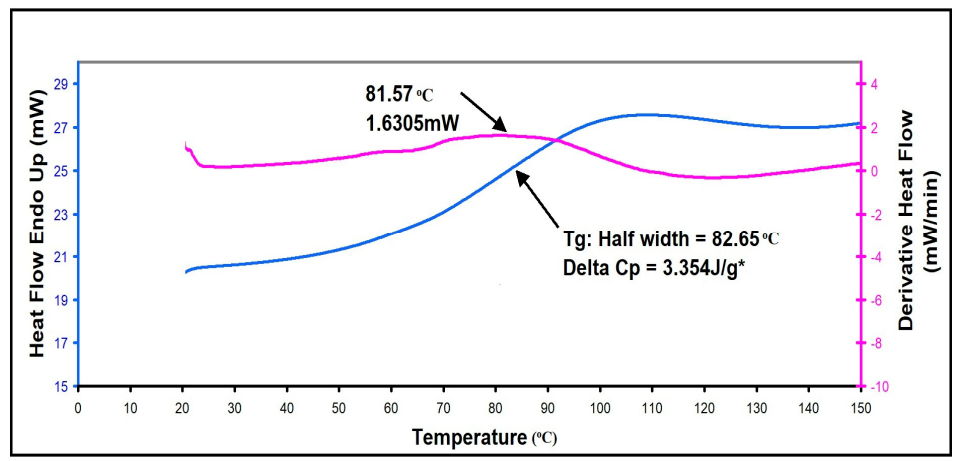

Figure 9: DSC curves of sugarcane lignin (weight $=7.4 \mathrm{mg}$; temperature rate of $20{ }^{\circ} \mathrm{C} \mathrm{min}{ }^{-1}$; atmosphere $\mathrm{N}_{2}$ )

\section{Thermal characterization by DSC}

Figures 8 and 9 show the differential scanning calorimetry (DSC) analysis for the kraft lignin and sugarcane lignin. Endothermic and exothermic events, along with glass transition changes, were obtained. ${ }^{5}$

The DSC analysis of kraft lignin and sugarcane lignin reveals a distinct endotherm around $80{ }^{\circ} \mathrm{C}$ in the first heating stage, which results in a $\mathrm{T}_{\mathrm{g}}$ of $81.3{ }^{\circ} \mathrm{C}$ for kraft lignin and a $\mathrm{T}_{\mathrm{g}}$ of $82.3{ }^{\circ} \mathrm{C}$ for sugarcane lignin, which is recognized as a $\mathrm{T}_{\mathrm{g}}$ characteristic of a natural polymer. Lignin is moderately stable at elevated temperatures due to its highly aromatic backbone and has a very interesting thermal behavior because it can act as a thermoplastic as well as a thermoset. ${ }^{33}$ However, in the second stage of heating, no significant event was found up to 200 ${ }^{\circ} \mathrm{C}$. The disappearance of $\mathrm{T}_{\mathrm{g}}$ in the second stage can happen if lignin undergoes selfpolymerization and cross-linking during the first stage of heating. In this way, lignin turns into a thermoset material. ${ }^{33}$ Pucciariello et al. analyzed the DSC curves (obtained by heating from $60{ }^{\circ} \mathrm{C}$ to $200{ }^{\circ} \mathrm{C}$ at a rate of $20{ }^{\circ} \mathrm{C} \mathrm{min}{ }^{-1}$ ) and reported that the $\mathrm{T}_{\mathrm{g}}$ obtained was around $60{ }^{\circ} \mathrm{C} .{ }^{33}$ The difference between the results could be explained by the effect of chemical structures on the thermal properties of lignins. According to Kadla, ${ }^{41}$ the glass transition temperature for hardwood lignin is $83.3{ }^{\circ} \mathrm{C}$. For sugarcane lignin, no result is provided in the literature.

\section{D ${ }^{13} \mathrm{C}$ NMR characterization}

NMR provides an easy tool for the characterization of several functional groups, including acid and methoxyl groups, phenolic and aliphatic units. The ${ }^{13} \mathrm{C}$ NMR spectrum can be divided into three main regions. The first region, delimited around 200-165 ppm, covers the carbon atoms of carbonyl groups. The second region, which is bounded by $165-100 \mathrm{ppm}$, is related to aromatic and olefin carbon atoms. The third region, which extends between 100-20 ppm, is related to aliphatic carbon atoms $(\alpha, \beta, \gamma$ and methoxyl). ${ }^{36,37}$ Freitas et al. ${ }^{44}$ published a study about the ${ }^{13} \mathrm{C}$ NMR analysis of rice hull biomass. ${ }^{44}$ The sugarcane lignin in our study and the rice hulls had almost the same characteristics because they were not submitted to a strong cellulose extraction process, such as kraft lignin. Residues of cellulose and hemicelluloses were identified. A parallel was made between the kraft and sugarcane lignins and the rice hull biomass. Cellulose and hemicellulose residues were identified in both samples. Besides, the kraft lignin showed a lower quantity of these residues than the sugarcane lignin. The main structures studied by ${ }^{13} \mathrm{C}$ NMR are shown in Figure 10, where a polymer backbone of lignin is shown, with the groups of $-\mathrm{OCH}_{3}, \mathrm{C}_{\alpha}, \mathrm{C}_{\gamma}$ and $\mathrm{C}_{\beta}$ and the cellulose backbone with the carbons identified.

Figure 11 shows the ${ }^{13} \mathrm{C}$ NMR spectrum of kraft lignin and Table 9 shows the signal assignments for the ${ }^{13} \mathrm{C}$ NMR peaks of kraft lignin and sugarcane lignin. In the spectrum from Figure 11 , it is possible to identify residues of cellulose and hemicellulose. The content of cellulose residues is around $5.8 \%$ by weight, with signals centered at 73.2 and $84.7 \mathrm{ppm}$. In the region of $\mathrm{C} 1$ - cellulose, there is a superposition with more intense signals corresponding to $\mathrm{C}-2 / \mathrm{C} 6$ in $\mathrm{S}$ lignin (a broad signal centered at $104.9 \mathrm{ppm}$, and a content of $8.7 \%$ by weight). Hemicellulose residues display peaks centered at $18.8 \mathrm{ppm}$ (with $1.0 \%$ by weight) and at $174.0 \mathrm{ppm}$ (with $1.2 \%$ by weight). Methoxyl groups $\left(-\mathrm{OCH}_{3}\right)$ show $16.9 \%$ by weight and a corresponding signal centered at $55.7 \mathrm{ppm}$. Aromatic regions represent $41.2 \%$ by weight, with corresponding signals between 
113.5-156.2 ppm. Specifically, C1 syringyl and C1 guaiacyl correspond to $20.7 \%$ by weight and their signals are centered at $137 \mathrm{ppm}$, and the signals of C3 and C4 guaiacyl are located at 147.5 ppm. ${ }^{42}$ The aromatic region of kraft lignin is between 97-156 ppm. The C3/C5 S carbons appear at $152.8 \mathrm{ppm}$ and $115 \mathrm{ppm}$. C3 carbons are characterized basically by $\mathrm{G}$ and $\mathrm{S}$ structures, and $\mathrm{C} 4$ and $\mathrm{C} 5$ carbons are related to $\mathrm{G}$ units, with the prevalence of guaiacyl and syringyl units in the lignin. The presence of cellulose has also been observed between 89-71 ppm. Compounds like cellulose products are referred to as contaminants. ${ }^{34,35}$

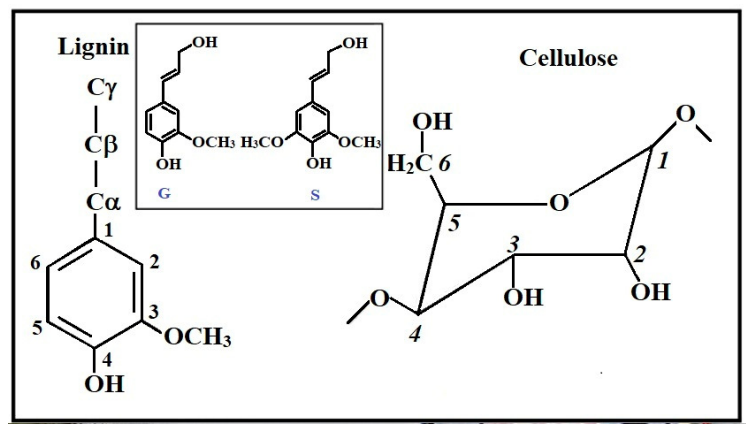

Figure 10: Structures of lignin and cellulose biomass analysed by ${ }^{13} \mathrm{C}$ NMR (S corresponds to syringyl lignin and G corresponds to guaiacyl lignin $)^{41}$

Table 9

Signal assignments for ${ }^{13} \mathrm{C}$ NMR of kraft lignin and sugarcane $\operatorname{lignin}^{33,39}$

\begin{tabular}{cc}
\hline Chemical shift $(\mathrm{ppm})$ & Assignments for kraft and sugarcane lignin \\
\hline$>172$ & $\mathrm{C}-\mathrm{OOR}$ \\
168 & $\mathrm{C}_{\gamma}$ \\
$139-155$ & Aryl C-OR \\
152.2 & $\mathrm{C}-3 / \mathrm{C}-5, \mathrm{~S}$ \\
$148-149.2$ & $\mathrm{C}-3, \mathrm{G}$ \\
$144-145$ & $\mathrm{C}-4, \mathrm{G}$ \\
$123-139$ & Aryl C-R \\
138 & $\mathrm{C}-4, \mathrm{~S}$ \\
134 & $\mathrm{C}-1 \mathrm{~S}$ and $\mathrm{C}-1 \mathrm{G}$ \\
130 & $\mathrm{C}-2 / \mathrm{C}-6, \mathrm{H}$ \\
125 & $\mathrm{C}-1, \mathrm{PC} / \mathrm{PC}$ ester \\
122 & $\mathrm{C}-6$ \\
119 & $\mathrm{C}-6, \mathrm{G}$ \\
115 & $\mathrm{C}-3 / \mathrm{C}-5$ \\
111 & $\mathrm{C}-2, \mathrm{G}$ \\
$103-104$ & $\mathrm{C}-2 / \mathrm{C}-6, \mathrm{~S}$ \\
$96-117$ & Aryl C-H \\
$\sim 83$ & $\mathrm{C}_{\beta}$ \\
$\sim 76$ & $\mathrm{C}_{\alpha}$ \\
$\sim 69$ & $\mathrm{C}_{\gamma}$ \\
$49-65$ & $-\mathrm{OCH}_{3}, \mathrm{~S}$ and G \\
30 & Aliphatic $(\alpha / \beta$-methylene in propyl side chains \\
\hline
\end{tabular}




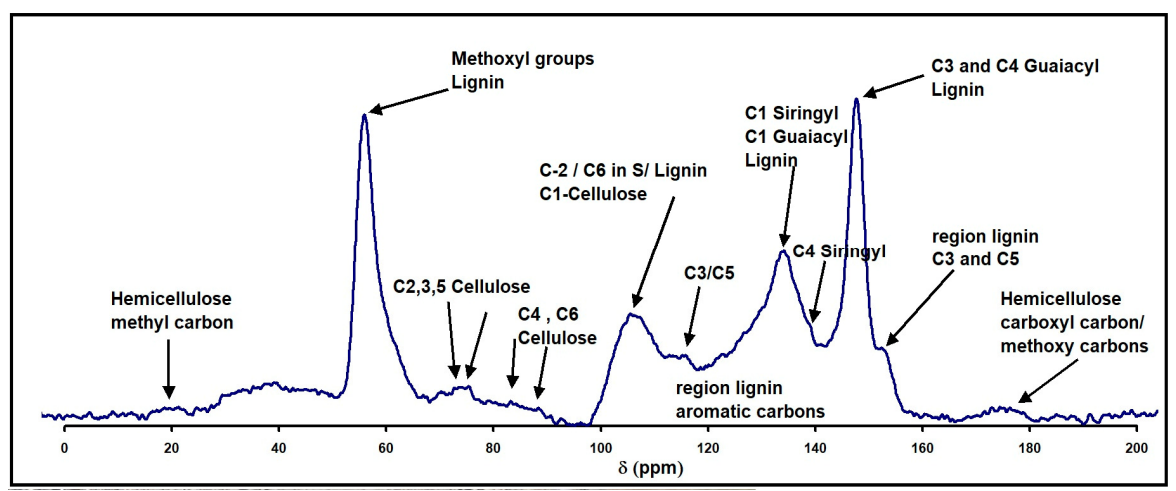

Figure 11: $1 \mathrm{D}{ }^{13} \mathrm{C}$ NMR spectra of kraft lignin

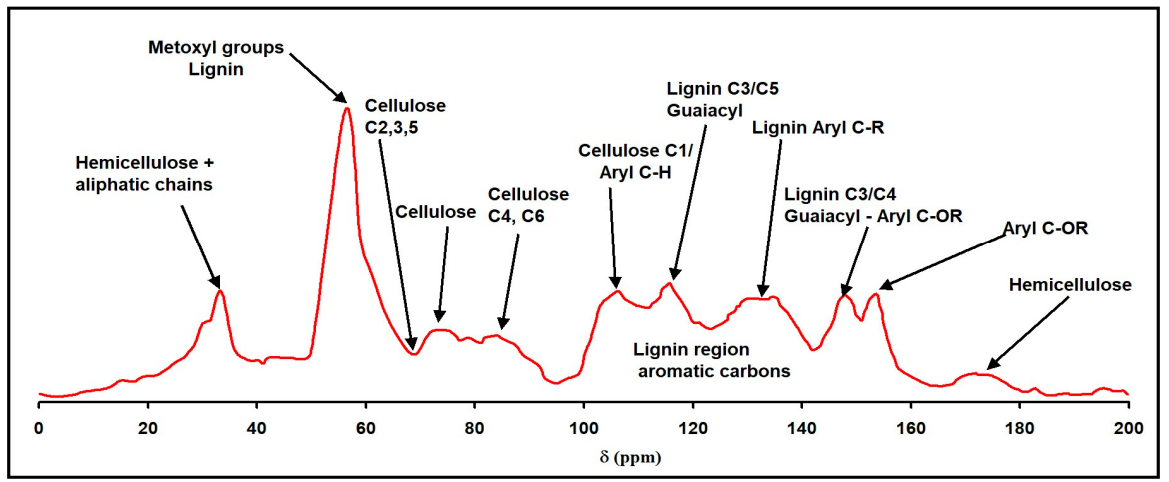

Figure 12: $1 \mathrm{D}{ }^{13} \mathrm{C}$ NMR spectra of sugarcane lignin

The main signal assignments for ${ }^{13} \mathrm{C}$ NMR of sugarcane lignin are shown in Figure 12 and Table 9. The region at $30 \mathrm{ppm}$ corresponds to aliphatic chains, their content being around $9.09 \%$ by weight. The region at $49-70 \mathrm{ppm}$ is attributed to $-\mathrm{OCH}_{3}$, with a content of $22.17 \%$ by weight. The region between 70-90 ppm corresponds to $\mathrm{C}_{\beta}$, $\mathrm{C}_{\alpha}$ and $\mathrm{C}_{\gamma}$, with $3.61 \%, 2.45 \%$ and $4.80 \%$ by weight, respectively. In this region, the resonance lines are superimposed on a signal of cellulose residue. The region between 100-111 ppm corresponds to aryl $\mathrm{C}-\mathrm{H}$, with the content of $6.57 \%$ by weight. The region between $110-120$ ppm corresponds to $-\mathrm{C}$ in guaiacyl, with the content of $8.50 \%$ by weight. Guaiacyl (G) residues were verified by the signals at $153.7 \mathrm{ppm}$ (C-3, G) with $4.4 \%$ by weight, 147.9 ppm (C-4, G) with $6.1 \%$ by weight, and $134.3 \mathrm{ppm}(\mathrm{C}-4, \mathrm{G})$ and $130.2 \mathrm{ppm}(\mathrm{C}-1, \mathrm{G})$ with $14.1 \%$ by weight. More guaiacyl signals can be observed at 116.3 ppm $(\mathrm{C}-6, \mathrm{G})$ with $8.5 \%$ by weight and at 106.3 ppm (C-2, G) with $6.5 \%$ by weight. A superposition of the resonance lines due to $\mathrm{C} 1$ cellulose residues and $\mathrm{C}$-2 from guaicyl residues is observed. ${ }^{36,42,44}$ A signal corresponding to hemicellulose residues appears at $172.3 \mathrm{ppm}$ with $2.6 \%$ by weight.

Although not illustrated in the spectra of Figures 11 and 12 for kraft and sugarcane lignins, the populations of carbonyl groups and aryl ether, condensed aryl, aryl, aliphatic side-chain related to $\mathrm{C}_{\alpha}, \mathrm{C}_{\beta}$, and $\mathrm{C}_{\gamma}$ carbons, methoxy and aliphatic carbons are identified at $\sim 172,141-152,123-140$, 110-123, 83-61, 55 and 30 ppm, respectively (see Table 9). ${ }^{36,37,44}$

\section{CONCLUSION}

After the purification process, kraft lignin and sugarcane lignin were verified to be suitable as a renewable raw material for manufacturing carbon materials. The results from the analyses have shown that the investigated lignins are in accordance with the required specifications for the use in processes to obtain precursors for carbon materials. The results obtained for ash contents are $0.06 \%$ for the kraft lignin and $0.09 \%$ for the sugarcane lignin. The volatile material is below $5 \%$ at $250{ }^{\circ} \mathrm{C}$ and no dross particles with the diameter above $1 \mu \mathrm{m}$ were found. Both types of lignin have high carbon content: kraft lignin 
showed $62.36 \%$ and sugarcane lignin $-58.20 \%$. The second derivative FTIR spectra showed that the intermolecular and intramolecular interactions between the hydroxyl groups in sugarcane lignin are stronger than in kraft lignin. This behavior supports the higher thermal stability and higher activation energy observed for sugarcane lignin.

Analyses by ${ }^{13} \mathrm{C}$ NMR provided a picture about the composition of kraft and sugarcane lignin and also showed cellulose contaminants. The results of all the analyses of kraft lignin revealed values typical for hardwood, and those of sugarcane lignin showed characteristics of softwood lignins, in spite of the fact that sugarcane is a grass.

The final consideration is that the evaluated lignins have a great potential to be used as raw material precursors for the production of valuable carbon materials, such as carbon fiber, based on their availability, sustainability, low cost and high carbon yield.

ACKNOWLEDGMENTS: The authors would like to thank FIBRIA for supplying the raw lignin used in their study. Thanks are also due to Dr. George Jackson da Rocha of CNPEM for valuable discussions. Useful suggestions by Dr. Roberto David Martinez Garcia are appreciated. This study was financed in part by the Coordenação de Aperfeiçoamento de Pessoal de Nível Superior Brasil (CAPES) - Finance Code 001.

\section{REFERENCES}

1 J. Zakzeski, P. C. A. Bruijnincx, A. L. Jongerius and B. M. Weckhuysen, Chem. Rev., 110, 3552 (2010), https://doi.org/10.1021/cr900354u

2 P. Peng and D. She, Carbohyd. Polym., 112, 701 (2014), https://doi.org/10.1016/j.carbpol.2014.06.068

3 P. Peng, M. Z. Zhai, D. She and Y. F. Gao, Carbohyd. Polym., 133, $117 \quad$ (2015), https://doi.org/10.1016/j.carbpol.2015.07.009

4 Y. F. Gao, H. T. Wang, J. H. Guo, P. Peng, M. Z. Zhai et al., Polym. Degrad. Stabil., 126, 179 (2016), https://doi.org/10.1016/j.polymdegradstab.2016.02.003

5 A. Awal and M. Sain, J. Appl. Polym. Sci., 122, 956 (2011), https://doi.org/10.1002/app.34211

6 C. A. B. Cateto, PhD Thesis, University of Porto, Portugal, December 2008.

7 L. B. Brenelli, F. Mandelli, A. Zerlotti Mercadante, G. Jackson de Moraes Rocha, S. Aparecida Rocco et al., Ind. Crop. Prod., 83, 94 (2016), https://doi.org/10.1016/j.indcrop.2015.12.013

8 J. Luo, Master of Science Thesis, University of Maine, 2010.
9 K. S. D. Nunes, L. C. Pardini and N. P. Alves, Procs. $2^{\text {nd }}$ Brazilian Conference on Composite Materials - BCCM2, September 15-18, 2014.

10 J. L. Braun, K. M. Holtman and J. F. Kadla, Carbon, 43, $385 \quad$ (2005), https://doi.org/10.1016/j.carbon.2004.09.027

11 A. N. Zabaleta, PhD Thesis, Escuela Politécnica de San Sebastian Donostiako/Eskola Politeknikoa, 2012.

12 M. Funaoka, React. Funct. Polym., 73, 396 (2013), https://doi.org/10.1016/j.reactfunctpolym.2012.05.010

13 X. Xie, B. Goodell, D. Zhang, D. C. Nagle, Y. Qian et al., Bioresour. Technol., 100, 1797 (2009), https://doi.org/10.1016/j.biortech.2008.09.057

14 S. Kubo and J. F. Kadla, Biomacromolecules, 4, 561 (2003), https://doi.org/10.1021/bm025727p

15 G. C. Q. Marín, PhD Thesis, Universidad Pontifica Bolivariana, Medellín, 2009.

16 S. Laurichesse and L. Avérous, Progress Polym. Sci., 39, $1266 \quad$ (2014), https://doi.org/10.1016/j.progpolymsci.2013.11.004

17 K. Servaes, A. Varhimo, M. Dubreuil, M. Bulut, P. Vandezande et al., Ind. Crop. Prod., 106, 86 (2017), doi.org/10.1016/j.indcrop.2016.10.005

18 A. García, M. G. Alriols, G. Spigno and J. Labidi, Biochem. Eng. J., 67, $173 \quad$ (2012), http://dx.doi.org/10.1016/j.bej.2012.06.013

19 J. Chen, F. Shen, G. Lyu, G. Yang, N. Lu et al., Cellulose Chem. Technol., 52, 371 (2018), http://www.cellulosechemtechnol.ro/pdf/CCT56(2018)/p.\%20371-380.pdf

20 D. A. Baker and T. G. Rials, J. Appl. Polym. Sci., 130, 713 (2013), https://doi.org/10.1002/app.39273

21 J. F. Kadla, S. Kubo, V. A. Venditti, R. D. Gilbert, A. L. Compere et al., Carbon, 40, 2913 (2002), doi: 10.1016/S0008-6223(02)00248-8

$22 \mathrm{http} / / /$ compositesmanufacturingmagazine.com/2016 /01/state-of-the-composites-industry-lucintel-2016/6/

23 A. K. Naskar and R. M. Paul, Low-cost bio-based carbon fiber for high-temperature processing, ORNL/TM-2017/83, CRADA/NFE-15-05807, February 9, 2017.

${ }^{24}$ Q. Shen, T. Zhang, W. Zhang, S. Chen and M. Mezgebe, J. Appl. Polym. Sci., 121, 989 (2011), https://doi.org/10.1002/app.33701

25 D. J. Johnson, I. Tomizuka and O. Watanabe, Carbon, 13, 321 (1975), https://doi.org/10.1016/00086223(75)90056-1

26 S. Kubo and J. F. Kadla, J. Polym. Environ., 13, 97 (2005), https://doi.org/10.1007/s10924-005-2941-0

27 F. S. Baker, W. L. Grifftih and A. L. Compere, Automotive light weight materials FY 2005 Process Report, 2005, p. 187.

28 G. Ramasubramanian, Master of Science Thesis, Iowa University, 2013, <http://lib.dr.iastate.edu/etd $>$.

29 N. Bech, P. A. Jensen and K. Dam-Johansen, Biomass Bioenerg., 33, $534 \quad$ (2009), https://doi.org/10.1016/j.biombioe.2008.08.015

${ }^{30}$ T. P. Protásio, L. Bufalino, G. H. Denzin Tonoli, A. Motta Couto, P. F. Trugilho et al., Brazilian Journal of 


\section{KATIA SANTOS DAMACENA NUNES and LUIZ CLAUDIO PARDINI}

Forest Research - Pesquisa Florestal Brasileira, 31, 113 (2011)

$<$ http://pfb.cnpf.embrapa.br/pfb/index.php/pfb/article/v iew/200/211>.

31 Nuclear Magnetic Ressonance (NMR): $<$ https://www.bruker.com/products/mr/nmr.html $>$, accessed in 05/21/2016.

32 Z. Xia, L. G. Akim and D. S. Argyropoulos, J. Agric. Food Chem., 49, $3573 \quad$ (2001), https://doi.org/10.1021/jf010333v

33 S. Sen, S. Patil and D. S. Argyropoulos, Green Chem., 17, 4862 (2015), DOI: 10.1039/C5GC01066G

34 J. F. Kadla and S. Kubo, Composites: Part A, 35, 395

(2004),

https://doi.org/10.1016/j.compositesa.2003.09.019

35 S. N. A. Md Jamil, R. Daik and I. Ahmad, Materials, $\quad$ 7, $6207 \quad$ (2014), https://doi.org/10.3390/ma7096207

36 M. Foston, G. A. Nunnery, X. Meng, Q. Sun, F. S. Baker et al., Carbon, 52, 65 (2013), doi:10.1016/j.carbon.2012.09.006
37 J. S. C. Favaro, PhD Thesis, Universidade Estadual Paulista, 2015.

38 S. Kubo and J. F. Kadla, Biomacromolecules, 6, 2815 (2005), https://doi.org/10.1021/bm050288q

39 M. Poletto and A. J. Zattera, Mater. Res., 16, 70 (2013), doi: 10.1590/S1516-14392010000300016

40 J. F. Kadla and S. Kubo, Macromolecules, 36, 7803 (2003), https://doi.org/10.1021/ma0348371

41 M. Poletto, V. Pistor, R. M. C. Santana and A. J. Zattera, Mater. Res., 15, $421 \quad$ (2012), http://dx.doi.org/10.1590/S1516-14392012005000048 42 D. She, F. Xu, Z. Geng, R. Sun, G. L. Jones et al., Ind. Crop. Prod., 32, $21 \quad$ (2010), https://doi.org/10.1016/j.indcrop.2010.02.008

43 M. Traoré, J. Kaal and A. M. Cortizaz, J. Anal. Appl. Pyrol., 126, 1 (2017), https://doi.org/10.1016/j.jaap.2017.07.003

44 J. C. C. Freitas, T. J. Bonagamba and F. G. Emmerich, Carbon, 39, $535 \quad$ (2001), https://doi.org/10.1016/S0008-6223(00)00169-X 